\title{
Contradictory Representations of the Child Figure in the Media: JonBenét Ramsey Murder Case Retellings on YouTube
}

Sylwia Gryciuk

\section{(2) OpenEdition Journals}

Electronic version

URL: https://journals.openedition.org/ejas/16778

DOI: $10.4000 /$ ejas. 16778

ISSN: 1991-9336

Publisher

European Association for American Studies

Electronic reference

Sylwia Gryciuk, "Contradictory Representations of the Child Figure in the Media: JonBenét Ramsey Murder Case Retellings on YouTube", European journal of American studies [Online], 16-1 | 2021, Online since 27 April 2021, connection on 08 July 2021. URL: http://journals.openedition.org/ejas/16778; DOI: https://doi.org/10.4000/ejas. 16778

This text was automatically generated on 8 July 2021.

Creative Commons License 


\title{
Contradictory Representations of the Child Figure in the Media: JonBenét Ramsey Murder Case Retellings on YouTube
}

\author{
Sylwia Gryciuk
}

\section{Introduction}

1 On December 26, 1996 a little girl named JonBenét Ramsey was found dead in the basement of her upscale home. Throughout more than two decades which followed her murder, this previously unknown six-year-old has been referred to as-among others -“America's most famous little girl" (Oates, "JonBenét Ramsey") and even "the most famous murdered child in history" (Mills and Tracey). To this date, her still-unsolved killing has inspired numerous articles, books, documentaries, and TV movies. Writing for the Newsweek's special edition, JonBenét: Twenty Years Later, Jeremy Brown aptly observes that, "[o]ther high-profile murder cases, such as Caylee Anthony and Laci Peterson, have come and gone, but 20 years after her death, JonBenét's murder still haunts the nation." The case's notoriety has often been attributed to its sensational media coverage which accentuated the girl's participation in controversial child beauty pageants as well as the family's speculated involvement in her death. Over the years, JonBenét's pageant-style images-showing her wearing heavy make-up and costumes deemed inappropriate for a child-have been continuously used for commercial purposes, attracting the audience with a promise of scandal and mystery.

In this article, I take a look at an Internet community which-through the means of YouTube remixes-attempts to challenge the sensational narratives popularized in the mainstream media in order to rehabilitate the Ramsey family and recontextualize JonBenét herself. I briefly analyze not only the videos' content but also focus on various community strategies and efforts which facilitate video creation in the first place. By 
placing my findings in the context of research conducted by scholars interested in the mainstream media portrayals of the Ramsey case, I also attempt to show that the outcome of this online activism does not correspond fully with the intent, as the videos in question are quite often riddled with contradictions, coming close to complicity with the narratives which their authors try to subvert. Ironically then, as I try to reveal, the academic observations regarding the mainstream media narratives often apply to their remix "counter-narratives" as well, lending credence to the larger claim that contradictory media representations of children and childhood are an epitome of a farreaching, cultural problem.

3 My material and selected methods place my research at an intersection of new media studies, childhood studies, as well as studies on death and memorialization. First and foremost-considering its digital character-I attempt to present my material in light of the long-established as well as the newest studies of fandom and remix. New media researchers often view an online remix as a polemical device challenging narratives and values propagated in the mainstream media and mainstream culture. For this reason, a remix has attracted a considerable amount of attention of researchers involved with feminist studies, queer studies or broadly understood social justice. Although I do not deny that a remix may serve this purpose, I point out that a relationship between a remix, its source materials as well as the mainstream culture may be much more complicated.

4 Even though the authors of JonBenét remixes use a new media platform and tools to challenge the narratives promoted by mainstream media, their actual goal is a simultaneous sustaining rather than subverting of the preferred cultural narratives of a childhood ideal. Namely, while the popular Ramsey case narratives often focus on a sexualized child growing up in a corrupt family system, the vidders tend to explicitly reject this interpretation, centering their narratives on an inherently innocent child figure who is thriving in a healthy and loving environment. The brutal murder is then presented as a crime committed by a perverted outsider, rather than a climactic moment in a relationship strained by abusive parenting.

5 As I try to demonstrate, the remixes/vids seem to celebrate the cultural ideal of childhood innocence, the modern-day legacy of the Romantic and Victorian discourses of childhood. In this sense, they are not unlike many other instances of public mourning for high-profile strangers, as these often seem to focus on simultaneous mourning and celebration of cultural symbols and values that the famous dead has come to stand for (Harju, Gibson). Yet, many vids also employ erotically-charged aesthetics and narrative strategies characteristic of the mainstream media accounts of the Ramsey case. These contradictory representations of the child figure appear not to be an isolated phenomenon pertaining to an unusual online community, but one of the twenty-first century manifestations of cultural discourse of childhood featuring a seemingly irreconcilable combination of sentimental innocence and disquieting eroticism, giving rise to what James Kincaid called the "erotic child" (Child-Loving 4, 5).

6 Even though my research is concerned with media representations of JonBenét and her case, it does not attempt to propose an alternative, "correct" way in which this historical figure should be represented in media or elsewhere. As opposed to the vidders, I do not try to uncover "the real JonBenét" or act as "a voice for the voiceless." My primary concern is also not an in-depth ethical assessment of the mainstream or new media portrayals of JonBenét or children at large. Instead, the Ramsey case serves 
here as an illustration of the complicated dynamics which can arise in relations between the old and new media, as embodied in the form of an online remix.

It remains debatable whether one can remain ethically neutral when commenting on acts of brutal violence, especially those inflicted upon real people whose images have become public property. Admittedly, by conducting and publishing this research, I too become partially implicated in the circulation of various ethically questionable representations and interpretations of JonBenét and her murder. This complicated state of affairs is an inevitable consequence of researching topics related to violence. Nonetheless, I agree with Teresa Marcias who-commenting on her own researcheventually concluded that: "rather than searching for innocent places outside representation, we must tackle the very issue of representation, what it accomplishes, and what it makes possible" (37). Even though my research is not primarily concerned with ethics of representations, its conclusions can still be employed in a wider discussion on cultural representations of children, including the ethical ramifications. This article is concerned with media portrayals of a single historical event, and yet, I suggest that their implications reach far beyond what happened in the Ramsey home in 1996, as the Ramsey case has come to symbolize the cultural struggles to (re)define and (re)present such concepts as childhood, womanhood, or family.

\section{Background}

With over two decades of the elaborate media coverage in mind, it may seem surprising to come across a statement by a CNN correspondent which reveals that the media's original reaction to the Ramsey case was close to indifference: "In the news business, it was the sort of story you'd quickly dismiss-it didn't have a national feel to it. But when it emerged that the child had been a beauty pageant queen, the story became sexier. That's what we played up" (Schiller 88). Had it not been for the beauty pageants, would the Ramsey murder find its way into the American crime mythology? With such multifaceted cases as that of JonBenét's, it seems safe to assume that each of its aspects contributed to the eventual notoriety. Undoubtedly though, the strange appeal of child beauty pageants is what originally gave rise to the "media frenzy." In the months and years that followed JonBenét's death, the formal investigation launched by law enforcement officials was always accompanied by the mainstream media narratives depicting the Ramseys as only seemingly perfect but in truth a deeply dysfunctional family, of which the ever-present pageant footage was to be convincing proof. With time, the pageant imagery came to stand for the mixture of revulsion, dread, and fascination with which the murder is still often approached.

9 In their 2000 book, The Death of Innocence, JonBenét's parents refer to the media portrayal of their daughter as not only exploitative but also deeply deceptive:

some of the tapes had been slowed down to portray a flirting expression or to accentuate JonBenét's movements and make them look seductive. Suggestive music -not the music played at the pageant-had also been added, and presto, something innocent became something ugly. Many of the still photos had been doctored with eye shadow, heavy lipstick, and rouge. Our daughter's innocence had been lost. (Ramsey and Ramsey 51)

10 Yet, the Ramseys' attempts at rehabilitation of the pageant circuit's image proved to be mostly unsuccessful, and in the popular perception child beauty pageants have become the epitome of damaging parenting. Interestingly, even the Ramseys seemed to be 
viewing themselves as in some sense symbolic, portraying their daughter's death as a far-reaching tragedy that reveals a deeper social crisis. In their notorious CNN interview Patsy Ramsey argued that the murder/abuse accusations directed against her family by the press and the public are a symptom of pessimism that had been spreading across the country in the aftermath of several high-profile murder cases that shook the Americans in the early 1990s (the cases of O.J. Simpson and Susan Smith). Speaking of these tragedies, she concluded that "America is suffering because we have lost faith in the American family" ("Interview with Parents"). Yet, in her view it was not the family itself that needed some scrutiny-or at least not their type of family. "We are a Christian, God-fearing family. We love our children. We would do anything for our children," she assured the public ("Interview with Parents"). Her point was clearperpetrators were to be looked for elsewhere, beyond the family.

11 The nation-wide interest in the Ramsey case and its media representations has reverberated in the academic community since the 1990s. Left-leaning academics such as Henry Giroux-a renowned cultural critic and educator-argue that that the Ramsey murder acquired such notoriety as it challenges the American myth of the white, (upper) middle-class family as an embodiment of success and safety. In Giroux's words: "JonBenét 's murder jolts the public because it shatters the assumption that the primary threat to innocence lies outside the family in the image of the sexual pervert. This murder also challenges the assumption that privileged families are immune to accusations of child abuse or neglect" (37). The Ramsey case (media) phenomenon has also attracted the attention of scholars and commentators working at an intersection of childhood, gender, and feminist studies whose primary goal was a confrontation with JonBenét's pageant persona and its social causes and consequences. In her article discussing the case's true crime narratives, Joyce Carol Oates argues that the magnetic power of JonBenét's mystery stems not only from the mysterious circumstances of the child's death but also from the mysterious circumstances of her life as manifested in the pageant imagery. As Oates writes, "[p]art of the power of JonBenét Ramsey as a symbolic presence in contemporary American consciousness is the paradox of what she, or her image, might mean .... Is the perversity of her image exclusively in the eye of the beholder?" ("The Mystery of JonBenét Ramsey"). This question of agency and intentions of the beholder (understood as both an individual and a system of power relations) is, in fact, a central issue in many scholarly inquiries into the Ramsey case phenomenon. By way of example, James R. Kincaid views JonBenét as a perfect illustration of his thesis according to which Anglophone societies are in denial of their fascination with the concept of an erotically enticing child, of which the media narratives reporting on child abuse cases are one of the proofs. As Kincaid evocatively writes in one of his press articles:

It probably shouldn't surprise us that JonBenét, like Roderick Usher's sister, won't stay buried. It's the return of the repressed all over again, here before us, strutting its stuff and doing its cultural work because we so badly need it. Where else can we find forbidden material served up to us in ways we can both enjoy and disown? We have to deal with a most uncomfortable heritage: an 'innocent' child who is also deeply eroticized. ("Little Miss Sunshine...")

12 Diana York Blaine, Professor of Gender and Sexuality Studies, evokes the same sentiment in her article "Necrophilia, Pedophilia, or Both?: The Sexualized Rhetoric of the JonBenét Ramsey Case." As she argues, "JonBenét's tight skin, lack of body fat, and youthful glow are exactly what make her beautiful to us. She is no pedophile's fantasy- 
she is ours" (54). Importantly, Blaine's analysis adopts a much more feminist angle, presenting JonBenét's gender as the key to understanding the nation-wide interest in her story. In Blaine's view, the fact that the tabloids reporting on the Ramsey case sold in such high quantities among average Americans constitutes a proof that society at large denies its fascination with the image of a sexualized female child which, as she posits, points to a deep-seated problem of objectification that all women and girls fall victim to when living in a male-dominated society. Blaine further substantiates this claim by drawing a comparison between tabloid narratives reporting on JonBenét's case with those featuring accounts of Princess Diana's life and death. As she asserts, although they differed in their age and social status, the tabloid narratives managed to reduce them both to the figure of an always youthful, passive princess-an object of male desire (54).

JoAnn Conrad, Professor of Anthropology and Folklore, reaches a similar conclusion in her comparative analysis of the tabloid accounts of the two stories, calling their fairytale narrative base "a princess paradigm." As she contends, both tabloid accounts borrow narrative schemes from such well-known fairy tales as "Cinderella," "Snow White," or "Sleeping White," and yet-to attract the readers' attention-their aim is not a predictable retelling but deconstruction of the familiar narratives tropes, and so the anticipated happy ending is replaced with a voyeuristic display of passionate, abusive relationships leading to a death of a helpless female $(127,141)$. What can be drawn from Conrad's analysis is the conclusion that fairy-tales (with their skewed gender power relations) do not belong exclusively to the realm of childhood, but are in fact a tempting narrative base helping adults to semantically organize complex events and relations that often elude a simple classification (127). On a smaller scale, it also reveals the magnetic power of JonBenét's story and her image(s), which are still prone to appropriations and resulting misrepresentations.

Such mainstream media narratives of the Ramsey murder have always been accompanied by some semi-organized, Internet-based critique, as the case has had a significant online presence from the time the news of it first broke out in early 1997. In her Guardian article Michelle Dean presents the Ramsey case as the stimulus which started the now-familiar phenomenon of "online detective"-"It was, in a sense, America's first crowd-sourced murder mystery," she concludes ("American Obsession"). Nonetheless, the criminal aspect of the murder is not the only magnet attracting the Internet users. Even though the identity of the murderer is in some way important to all those contributing to the continuous online presence of the Ramsey case, some of the users seem to be placing the emphasis not so much on the intellectual closure, i.e. gaining knowledge of the crime, as on the emotional one-i.e. ensuring that JonBenét's memory is being kept alive in what they deem a proper way.

Although the following analysis is concerned primarily with the YouTube presence of what I call the JonBenét memorial community, their activity is not restricted to this platform alone, and their origins actually predate the launching of this largest videosharing website. The first attempts at forming an online community devoted to the preservation of JonBenét's memory probably date back to the year 2004 when the (currently unavailable) memorial website Remembering JonBenét Ramsey was created. Colored in light shades of pink, the homepage featured a banner with a pageant-style image of JonBenét and the inscription reading: "In Loving Memory of JonBenét Patricia Ramsey/August 6, 1990-December 25, 1996." Below one could find more details 
regarding the site's mission and operation manner, which stressed its grass-roots, nonprofit character:

This website is to remember JonBenét and keep her memory and case alive. We are not affiliated with the Ramsey family or any investigators on the case. No media or text may be taken from this website without permission from the webmistress. This website is NOT an official site and we are not aquainted [sic] with any member of JonBenét 's family.

IMPORTANT NOTE: This is NOT a profitable site and donations are used to keep this site up and running and nothing more. Thank you!

The page consisted of a few sections with some biographical information on JonBenét, a multimedia repository, and a discussion forum. Yet, unlike most online discussion boards devoted to JonBenét, this one was not concerned exclusively with the murder investigation and resulting theories, as its most popular thread was devoted to "JonBenét's Life" where users "[could] talk about JonBenét's short life and her accomplishments." In this sense, the page was closely reminiscent of a fansite, and it was indeed organized similarly to two other (still existing) memorial sites dedicated to two Hollywood actresses who died in childhood-Heather O'Rourke: The Official Fansite and Judith Barsi: The Concrete Angel. Importantly, the similarities were not a result of a mere coincidence, as the three sites were loosely affiliated and shared some of the members. It then appears that JonBenét the memorial character is a figure combining elements of both a child murder victim and a child celebrity. Indeed, when coming in contact with the online memorial activity devoted to her it may be surprising to realize that, unlike Heather O'Rourke or Judith Barsi, JonBenét became recognizable only after -and because of-her brutal death.

Even though its host page is now gone, the official Facebook page for Remembering JonBenét Ramsey is still accessible, if mostly inactive. In the (dated) "About" section the admin(s) place the community in noble opposition to the mainstream media, which are in turn cast as the villain spreading distorted narratives of JonBenét's life:

Our website strives to keep the memory of six-year-old JonBenét Ramsey and her investigation alive after 13 years since her brutal murder in December 1996. We remember JonBenét as a typical child who loved life, her family and her friends. She was not just a 'beauty queen' like the media has made her out to be over the years, but also an average American girl who enjoyed many other activities such as rock climbing and the playing the violin.

What is more, the section also aims to advertise the website's unique asset, as well as invite potential newcomers:

Welcome to the OFFICIAL facebook page to the website Remembering JonBenét (JonBenét -ramsey.com)/ An online community with over 1,000 members, an active forum, magazine/newspaper archive, gallery with thousands of images and much more, we are the largest database on the net about the child herself./ Come join us as we work together to create a reflection on the life of an ordinary child who became a icon in 6 short years.

19 Rather than testifying to the declining interest in JonBenét 's story, the fact that the memorial website is currently unavailable may, in fact, reflect larger cultural changes that have occurred in the Internet use in the recent years. As social media began to rise, separate discussion boards and fansites have gradually lost their appeal. Consequently, nowadays, the memorialization activity devoted to JonBenét exists mostly in the form of small-scale commemorative pages and efforts scattered around platforms such as YouTube, Facebook, Instagram, Reddit, or Tumblr. Importantly, other 
murdered and missing children of Anglophone societies are also becoming subjects of similar commemorative/awareness activity, although usually on a much smaller scale. Most notable examples include Madeleine McCann, the British girl who became the most recognizable missing child in the world following her 2007 disappearance from a vacation resort in Portugal, and Caylee Anthony, the American toddler whose death was the subject of a high-profile 2011 murder trial. Less recognizable missing/ murdered children often figure as a collective protagonist, and their stories are featured on profiles operating under generic names referring to lost innocence as well as the hope of an afterlife reunion.

The wider context of the commemorative/awareness practices devoted to missing and murdered children is deserving of separate studies approaching this activity from the historical as well as cultural perspective. What is perhaps also worth investigating is the question of whether these commemorative/awareness practices help with finding legal resolutions to the cases they highlight or with preventing further crimes. Their perception among a wider Internet audience as well as family and friends of the victims constitutes another interesting research area. Although intriguing on many levels, these questions remain beyond the scope of my study, and this article focuses exclusively on YouTube memorial videos devoted to JonBenét-currently, the most semantically and structurally complex form of online memorials devoted to, arguably, any other late American child.

21 As they are not a case of a public outpouring of private grief but rather an example of public mourning for high-profile strangers, JonBenét Ramsey memorial videos can be classified as belonging to a distinct subgenre of the online memorial. Although public mourning for de facto strangers is clearly not a new phenomenon, the growing accessibility of the Internet has increased the visibility of such practices. When analyzed in the context of contemporary mourning rites in America, JonBenét videos may then also be perceived as a facet of what Erika Doss calls a "memorial mania"-the excessive preoccupation with public memorialization practices which are as much personal as they are sociopolitical. As Doss asserts, "today, the pace of commemoration has quickened, and the number of memorials has escalated, because growing numbers of Americans view public art as a particularly powerful vehicle of visibility and authority" (37). Although Doss's seminal book does not offer an analysis of digital memorials, I suggest that her conclusions can easily be applied to the online realm as well. In selected aspects, JonBenét memorial vids may be viewed as digital semiequivalents of temporary memorials erected in the aftermath of other highly publicized, brutal child murders, such as those of Carlie Brucia or Sandra Cantu, which Doss mentions in her book (66).

When JonBenét YouTube videos are being viewed as memorials it is important to face the question of who, or what is actually being memorialized through them. Can the videos be classified as expressions of grief at all? If so, what is the object of grief? As researchers concerned with death and grief studies point out, living in technologically advanced societies often leads to paradoxical encounters with death. While the physical death manifested in the form of sick and dead bodies remains concealed and tabooed, the process of dying is being constantly reenacted in its media simulations. These depictions-even if detailed and graphic-usually contain death images within certain aesthetic frameworks, thus creating an impression of death very different from the ones experienced within communities still retaining the physical proximity of the dead 
and dying (Cann, Doss, Gibson). Margaret Gibson observes that such media-mediated contact with the concept of death often leads to individuals becoming first affected by fictional deaths or deaths of practical strangers, i.e. celebrities (415). Some of these deaths result in what appears to be a publicly manifested out-pouring of grief, with the most striking example being the aftermath of Princess Diana's passing.

In his study on the public response to Diana's death, Richard Johnson concludes that the Princess "was clearly the object of many transferred feelings, feelings that had little to do with her own life and death, and everything to do with the lives of members of her public" (31). The princess's death is then presented as a pretext for public manifestation of festering grief directed at other objects, and thus a grief which has not been properly acknowledged-either by the individual experiencing it or by the society at large. In the latter case, we would be speaking of what Kenneth J. Doka famously recognized as "disenfranchised grief." In turn, Margaret Gibson views that emotional responses to deaths of high profile strangers as motivated not by concrete losses experienced individually but by a more elusive sense of loss which is experienced collectively on a symbolic level. As she concludes: "When public/celebrity figures die what is lost, is the link between collective myths and ideals, and their embodiment in real flesh and blood people" (420). Anu Harju adopts a similar perspective in her study on YouTube memorials dedicated to Steve Jobs, arguing that: "[a]lthough social construction of the past and also of emotion is common in memorials of any type, what is being mourned in the online commemoration is an emblem, a representative, rather than a person in their wholeness" (136). Having these observations in mind, I propose that the perceived media eroticization of JonBenét's image as well as resulting sensationalization of her story is construed by the vidders as an attack on the cultural ideal of childhood as a time of innocence and purity. This attack is then also experienced as a kind of loss. JonBenét memorial vids may then be understood to be both-a public mourning of the cultural ideal as well as a simultaneous attempt at its reinstatement.

In Anglophone societies, the cultural construction of childhood as a time of innocence and purity dates back at least to the Romantic period. As observed by Judith Plotz, Romantic authors were themselves trapped in a paradoxical situation-although they were seemingly celebrating childhood, their actual preoccupation lay with constructing an unattainable ideal of a child as an ever-beautiful visionary possessing unadulterated wisdom and a pure heart. This vision stood in stark contrast with the images of many actual children of the Romantic period whose lives were marked by abject poverty and child labor-thus not very different from the harsh, everyday realities of their adult counterparts $(4,6)$.

Interestingly, the Romantic discovery of the child figure was also closely connected with a fascination with their mortality. As argued by Franco Ferrucci:

If one wanted to locate in Western Literature the time of the momentous appearance of children as autonomous characters, endowed with a presence and a mystery of their own, one would spot the advent toward the very end of the XVIII century; and, at that point, the investigator would be struck by an unexpected discovery. He would realize, not without awe, that the children had to be heard because they were dying. The child is born in literature with a destiny of death in life. (117-118)

The echoes of the Romantic (as well as the very different, Puritan) vision of the child continued to flourish throughout the nineteenth century, giving rise to the figure of a 
"saintly child" (392) - exceptionally beautiful, pure at heart and often preserved in their innocence through premature death (Trensky 392, Wood 117-118). Yet, as claimed by Kincaid, this cultural fascination with the angel-like child figure inevitable leads to the creation of its unsettling double-the "erotic" child:

By insisting so loudly on the innocence, purity and asexuality of the child, we have created a subversive ego: experience, corruption, eroticism. More than that, by attributing to the child the central features of desirability in our culture-purity, innocence, emptiness, Otherness-we have made absolutely essential figures who would enact this desire. (Child-Loving... 4, 5)

Perhaps then, the paradoxical representations of JonBenét Ramsey- intermingling purity and innocence with implied eroticism-are another manifestations of the legacy of over two centuries of contradictory representations of the child figure in Anglophone societies.

In order to better explore the arguments presented above, I view JonBenét memorial videos as examples of a remix-a potentially polemical creation comprised fully out of various copyrighted materials to which their author has no legal claim. Importantly, the concept of a remix is also strongly connected with the concept of a fanvid-the audiovisual product of fannish activity constituting one of the central objects of analysis in fandom and remix studies. In the following analysis, I treat the memorial remixes as a hybrid genre, combining characteristics of a memorial video (an audiovisual material created to honor the memory of the dead) as well as a fanvid (a remix video presenting a narrative featuring fictional or fictionalized characters who are not the vidder's original creation) which I call a memorial vid.

In her theoretical conceptualization of the phenomenon, Virginia Kuhn observes that even though remix videos are often viewed as derivative by-products of fans' desire for entertainment, they can also operate as rhetorical devices entering into an argument with their source materials and the dominant cultural narratives by extension (5.1). At first glance, this observation corresponds to Francesca Coppa's famous proposal that "a vid is a visual essay that stages an argument, and thus it is more akin to arts criticism than to traditional music video" ("Women, Star Trek" 1.1). Yet, Kuhn is right in noticing that the emphasis on the visual-although quite common among remix/vidding researchers-provides a lacking definition, as remix videos actually function as an interplay of (at least) three different forms of expression. As Kuhn proposes: "I define remix as a digital utterance expressed across the registers of the verbal, the aural, and the visual. The affordances of the digital create a broader range of available semiotic resources through which one may speak; thus, remix is a form of digital argument that is crucial to the functioning of a vital public sphere" (1.5). I approach JonBenét memorial vids with similar theoretical assumptions, considering all the three vid components in the process of my analysis. However, determining the importance of a song choice (with its verbal as well as aural dimensions) is one of the crucial elements of my analysis. As noted by Coppa, a song's function is to "narrate and contextualize the reedited sequence, telling a new story or making an argument" "An Editing Room" 124). However, I suggest that Tisha Turk's claim that "music [understood as a combination of aural and verbal components] is a vid's most obvious and essential discursive feature" (95) is more apt, as it accentuates the special role that song choice has for the overall construction and reception of vids. 
What is more, I argue that JonBenét vids are an example proving that although a remix may be a form of digital argument countering its source materials, it may simultaneously attempt at sustaining rather than subverting of a cultural narrative that is being attacked in the mainstream media. In truth, the practice of vidding has attracted a significant amount of attention from researchers involved with feminist, gender, and queer studies who often see vidding as a fertile ground for production of narratives critical of the mainstream/traditional culture. Kuhn herself encourages the adoption of such a perspective when she claims that by reading "remix as digital argument, we could more productively link fan vids to other resistant practices that question the grand narratives of our time" (5.1). Although in many cases effective, I suggest that this kind of interpretative lens should be adopted with caution. Henry Jenkins is undoubtedly right when he notices that assuming that vidders are by definition critical of traditional values is limiting at best. As he writes in his seminal book: "[r]eaders are not always resistant; all resistant readings are not necessarily progressive readings" (35, italics in the original). Similarly, although JonBenét memorial vids often present a critique of the mainstream media narratives focused on the (symbolically perceived) Ramsey family, they simultaneously aim at preserving the grand narratives of the family and child(hood) ideals. In order to highlight this semantic complexity, my analysis also focuses on vid aesthetics-an area of inquiry whose importance remains largely underestimated as products of remix culture are mostly analyzed in terms of their argumentative and political dimensions (Schonig 2). As I attempt to demonstrate, a closer look at certain aesthetic choices favored by vidders highlights the often contradictory nature of their message.

\section{Analysis}

31 The following analysis is a result of my intermittent observation of the JonBenét memorial community which lasted for 13 years (2006-2019). During this time, I watched roughly one hundred JonBenét memorial vids published on YouTube, some of which have been removed or unlisted in the meantime. In order to select a representative analytical sample, I considered the following vid characteristics: overall popularity of each vid, the popularity and status of the vidders within the community, recurring themes and styles. I substantiate my claims based on the example of nine vids posted by eight different users in the years 2008-2018. Importantly, my analysis also encompasses elements external to the vids themselves, such as texts included by their authors in description boxes or comments left by the viewers. What is more, to flesh out the extended context, I briefly characterize the JonBenét memorial community itself.

The first representatives of the JonBenét memorial community started uploading their content on YouTube already back when this largest video-sharing platform was still in its infancy. Interestingly, it appears that from the very beginning the community has been dominated by teenage girls and young women, many of whom give an impression of being JonBenét's peers. This observation is consistent with the findings of researchers whose studies concerned online memorials created for family members, predominantly deceased children (Mitchell et al 420). It also corresponds with the recurring observation that not only are fanvids mostly made by women (Coppa, Turk), but so is media fandom in general largely female-dominated (Jenkins). 
restingly, the phenomenon of female-authored, non-fiction works centering around the sentimentalized figure of a deceased child is not a novel concept in the American context, as it dates back at least to the nineteenth century. As argued by Diana Walsh Pasulka, female-authored memoirs focusing on the life and death of a saintly child figure were then a popular nonfiction genre:

In the nineteenth century, women memoirists transformed conventional Protestant notions of the afterlife through a little studied genre of literature, child hagiography .... First, the authors couched the new theology of immortality in memoir form, and then they delivered it with the pathos that the sentimentality of the popular trope of child death aroused. Written primarily by white, middle-class Protestant women in the northeast, these peculiar biographies were immensely popular and are an overlooked factor in the liberalization of Protestant theology. (52) sociopolitical discourse, and it can both signal as well as bring about important cultural changes. Even though the legacy of online memorial videos dedicated to children is yet to be revealed, their aesthetics as well as interest in cultural dilemmas (such as the question of safety and agency of child citizens) suggest that they continue the traditions of narrative representations of deceased children that long-predate the digital revolution.

Admittedly, though, the channels of JonBenét vidders, are not always consistent in their message. In the early days of YouTube, most of them were characterized by an eclectic approach, being devoted to JonBenét and other famous late children as well as to typical teenage interests: celebrities, TV shows, music bands etc. Yet, the ones that stood the test of time often narrowed their scope of activity, and so the vidders who still post Ramsey-related content are likely to have their channels focused on memorial vids of various kinds. One of the most prolific JonBenét YouTube vidders is a case in point. Going by the name of TheDoorMouseTeapot, she has been active on YouTube since 2006 and, currently, her channel offers nearly sixty JonBenét memorial vids available for a public audience. Even though she used to regularly upload various lighthearted fanvids as well, nowadays TheDoorMouseTeapot's content consists almost exclusively of memorial vids commemorating dead celebrities and murdered children, primarily JonBenét. Interestingly, a number of JonBenét YouTubers focus nearly exclusively on famous late children, and their channels can be recognized by their telling names such as Gone Too Soon or xBeautifulAngelsx. Some vidders speak of their channels as it if they were part of a mission aiming at achieving something more than just providing the viewers with an aesthetic experience. For example, CherishEarthAngels introduces her channel in the following way: "My name is Dana! I'm a 21 year old from Ontario, Canada. I make tribute videos of children who've passed away and support videos for children with life-threatening illnesses" (About). Although in many ways vague, such descriptions are symptomatic of what appears to be a common conviction among the vidders who often imply that making, sharing and commenting on memorial vids is some form of social activism.

In the early days of YouTube, JonBenét memorial vids were often marked by formal and semantic simplicity, consisting mostly of random pictures of JonBenét played along a mournful tune. In this sense, they were not unlike many public memorial videos users publish to honor their loved ones. When viewed as an art form, such memorials rarely fall under the category of ambitious undertakings. Similarly as their apparent 
precursors, the American funeral videos, the vast majority of the memorial videos on YouTube do indeed "seem to be a grotesque corpus of sentimental kitsch" (Wahlberg 219). The funeral video's primary purpose is to arouse affect rather than provoke a thoughtful insight or action, and YouTube memorials-whether created for family and friends or high-profile strangers-are most often designed with a similar intent (Harju 133).

Yet, the growing amateur interest in video editing technologies as well as apparent peer pressure quickly raised expectations regarding vid quality. Similarly as in the case of standard fanvids, their message is no longer attractive unless it is wrapped up in an impressive form showing the author's skills, creativity, and technological know-how (Ciancia and Tosoni 47-49). As a result, contemporary JonBenét memorial vids often comprise an intricate mix of edited video and sound footage, images, and (most often) unrelated soundtrack which ranges in genre from pop to heavy metal and goth rock. Sources used for extracting materials in question include, among others, news reports on the case, documentaries about the case, TV interviews with the Ramsey family, TV movies based on the case, and images of the Ramseys available online (many of which were originally published by the mainstream media). Extracted clips and images circulate within the community itself. Some prove to be popular and special repositories are created to facilitate their distribution. In consequence, different vidders use the same clips for their vids, further adding to the sense that due to various similarities JonBenét vids belong to a genre of their own. As a result of this community effort, some vidders may not even be aware of the exact origins of some of the materials they use. What truly matters is maneuvering between various interpretations that they come to symbolize, with the final product being-a more or less coherent(counter)narrative of JonBenét's life and death, yet again supporting Jenkin's conclusion that vidding is "first and foremost a narrative art" (238).

Although JonBenét is not the only famous, deceased child who has become a subject of YouTube memorial vids, the vids dedicated to her are distinctly more complex and developed as a genre. The important difference setting them apart from those dedicated to other late children is their division into at least two subgenres: the socalled tribute videos and case videos, the latter appearing to be an exclusive JonBenét YouTube phenomenon. Tribute videos-a form common to all memorial vids-are simpler at their core, as they aim primarily at honoring the child's memory. Some contain an explicit call to the action of remembrance already in the titles: "Remember My Name," "I Want to Be Heard," "Hear Me" "Don't Forget Me," are just a few examples. The last vid ["Don't Forget Me (Remembering JonBenét Ramsey, 20 Years Later")] is set to Way Out West's song of the same title, and its key lyrics read as follows:

There's just one thing that I need to feel

Before I walk away against my will

Don't forget me (TheDoorMouseTeapot 0:18-0:51)

The vid's visual component-consisting largely of an interplay of the Ramsey home videos and regular pictures of JonBenét as well as a few pageant clips-creates the impression that this is indeed JonBenét revealing her final wish, the need to be remembered. 

manuals instructing the viewers as to how JonBenét should be remembered. "The Child the Media Forgot" is here a recurring theme. Splee331's video bearing such a title is complemented with the following description: "JonBenét was a happy little girl .... The media seemed to forget all that and only showed her as the child beauty queen, slowing down innocent footage of her performing in pageants, applying sexy music over the music that was played during the pageants and adding makeup to her photographs." Interestingly, the description appears to be a paraphrase of the accusations directed against the media in The Death of Innocence. And yet, the vid itself begins somewhat ironically, showing pageant footage of JonBenét introducing herself to proceed with a series of different pageant-related photographs and clips. Soon though, such an image is challenged by many home video clips and photographs capturing JonBenét in more casual settings. Incorporating home footage and photos from the Ramseys' private archive is indeed the most common strategy by which the vidders try to present JonBenét as an "average little girl," thus opposing the media's fixation on her pageant persona. Sometimes, aestheticized images of JonBenét's gravesite are also employed to highlight her innocence. For example, "No Address in the Stars $§$ Remembering JonBenét Ramsey" often intertwines such images with the Ramsey family pictures. The most evocative burial site photograph used presents a gravestone bearing the inscription reading: "LOVE, PURITY AND JOY/A GIFT TO HER FAMILY AND THE WORLD/HOME IN THE PEACE OF GOD” (NavyLittleMonster 01:06-01:09). Apart from emphasizing JonBenét's innocence, such an aesthetic choice constructs her as a modern day incarnation of the nineteenth century ideal of a saintly child (Trensky, Wood).

The attempts at recontextualizing JonBenét are often accompanied by attempts at rehabilitating the whole Ramsey family. Some vids are purposefully less JonBenétcentered, treating the Ramseys as a collective protagonist, while others are focused on a single member of the Ramsey family other than JonBenét, most often her mother. One of such vids is titled simply "Mother's Courage." To highlight its message, it is supplemented by a lengthy description defending the Ramseys-Patsy, in particular: "No matter how much Patsy said she loved her child and how precious her children were to her, very few believed she or John innocent. But Patsy, was a mother who deeply loved her children .... $\bullet$ [She] was a beautiful, strong and brave woman" (ForeverInXWonderland). The vid is set to Michael Bolton's "The Courage in Your Eyes," which was written as an actual tribute to Coretta Scott King, the wife of Martin Luther King, Jr. The visual component is comprised mostly of a slideshow including images of Patsy Ramsey in which she is presented as either a loving and happy mother or a grief-stricken but strong figure. At the end, we see a snippet from Patsy's interview in which she is talking about finding the motivation to continue living when tragedy strikes (03:18-03:56). The interview clip then fades into a photo of Patsy's flowerdecorated gravesite whose partially visible inscription reads, "Grace, Love, and Faithfulness/Through All” (03:56-04:00). The vid's overall message appears clear-Patsy Ramsey is an admirable, inspirational character who can teach us all a lesson about persistence in the face of adversity.

In the case of such unapologetically pro-Ramsey vids, one is almost certain to find some blunt, if not crude comments expressing a view opposing to the author's, as illustrated by the following example-"If anyone thinks there was an intruder, i suggest you make an appointment with the nearest doctor to get your head examined." Another Patsy 
tribute-“Patsy Ramsey tribute-Iris (PLEASE WATCH)"-has comments which are even more emotional, reflecting their authors' indignation at the mere thought of a tribute honoring Patsy Ramsey-“Wow, what a joke....a tribute to a child killer!!”-reads one of them. such emotional responses. In these vids the Ramseys are usually implied to be victims of three parties-the sadistic killer, the incompetent police officers and, finally, the cynical media. The image which eventually surfaces in many tribute-type videos is that of the Ramseys as an emblematic family and JonBenét as "a little girl next door" whose life was ended by an unknown outsider. In the vids this mysterious third party is often symbolized by the images of an open basement window, a speculated point of entry for JonBenét's alleged intruder killer. Interestingly, as a result of this strategy, rather than recontextualized as an "average littale girl," JonBenét herself is once again being portrayed as a semi-mythical character, operating more like a symbol than an actual child.

Some aesthetic choices favored by vidders only reinforce such an impression. For example, one of the popular song choices is "Once Upon a December," a piece composed for a 1997 animated movie inspired by the rumors surrounding the murder of Grand Duchess Anastasia Romanov. In the movie, eight-year-old Anastasia survives the assassination attempt at her life. Stripped of her princess identity, she now lives in poverty, having only a dim recollection of her royal heritage and glorious past. In the vids her voice is being appropriated by JonBenét character, and so the viewer is under the impression that it is indeed JonBenét singing from beyond the grave, mourning her lost princess identity and the exile from a marvelous kingdom. For example, in one of its segments, BeautifulSoul's vid includes a mix of the Ramsey family videos and snippets from TV reconstructions showing blurred footage of elaborate Christmas decorations and a little actress portraying JonBenét dancing in circles in slow motion. All of these is accompanied by a nostalgic, child-like voice singing in the background: "Someone holds me safe and warm/Horses prance through a silver storm/Figures dancing gracefully/Across my memory" (01:36-02:00). When presented in such a way, JonBenét is being yet again inscribed in what Conrad calls a "princess paradigm." Then, rather than countering the media narrative, the vidders, in fact, comply with it on their own terms.

Arguably, though, the vidder's complicity with the mainstream media narratives is most blatant in their consistent (re)incorporation of pageant imagery. In truth, the imagery is rarely used in an unmistakably inappropriate context (i.e. played along a song with explicitly erotic lyrics), and if this occurs, such practice usually meets with some form of criticism from the viewers. Still, it is common to see pageant footage incorporated in an ambiguous vid narrative, which often includes its use with songs containing subtle erotic references. For instance, there are currently at least nine JonBenét vids set to Lana Del Rey's "Young and Beautiful" available on YouTube. The song features a hypnotic chorus section with Del Rey singing: "Will you still love me/ When I'm no longer young and beautiful?/Will you still love me/When I've got nothing but my aching soul?/I know you will" (NikkiJ, 00:49-01:12). Many vidders using the song centre the entire vid around the juxtapositions made between the pageant and family album imagery. The narrative which implicitly emerges is of JonBenét vid character finding reassurance in her belief that there are people who will not 
remember her exclusively through the prism of the pageant persona. Yet, ironically, the vid character is also given a voice and perspective of a grown woman who is aware of her physical attractiveness and threats of instrumental treatment which it entails. She is then no longer depicted as an ignorant child, and neither are pageants an innocent pastime. Interestingly, such a vid formula seems to be a perfect illustration of Kincaid's argument that cultural emphasis on "innocence, purity and asexuality of the child" inevitably constructs "a subversive ego [of] experience, corruption, eroticism" (Child-Loving 4, 5).

Such an ambivalent, internally contradictory attitude towards JonBenét's pageant persona becomes especially evident in the more melodramatic vids, typically the socalled "case videos." Case videos are often much more sensational than the regular tribute videos, as they seemingly attempt at recreating the intense atmosphere of the initial phase of the murder investigation and the ensuing "media frenzy." Some even include crime scene/autopsy images, with the suggested aim of bringing the viewer's attention to the horrifying reality of JonBenét's death. Yet, sometimes their use seems much harder to justify. Hideochseek's "JonBenét: See Who I Am" is here an apt example. Set to a dramatic, metal ballad by Within Temptation, the video is filled with drastic imagery featuring video clips showing actresses playing JonBenét for various TV productions as well as the actual crime scene/autopsy photographs. The vid's description includes a quasi-warning, informing potential viewers that it may not be "a video for a sensitive person." Still, some of the 368 comments reflect the viewers' indignation. One such comment reads as follows-"this video is sick. you should b ashamed of yourself posting this.are u some kind of necrophiliac." Interestingly, we can also find comments bringing attention to the fact that the responsibility for the circulation of the graphic imagery cannot be put solely on the vid's author. As one user asserts, "I agree that posting her body online is horrific but you're all being hypocrites because you watched it because you wanted to see so shut the hell up!!!" Arguably then, to a greater or lesser extent, all of the vid's numerous viewers (including the author of this article) become in some way complicit in (re)contextualizing the violence inflicted on JonBenét as a form of spectacle.

Despite the heavy use of graphic imagery-or precisely because of it-hideochseek's video is one of the most popular JonBenét memorial vids on YouTube, having over 223, 000 views thus far. Interestingly enough, it is not the first time that drastic imagery associated with the Ramsey case is used to attract public attention. The autopsy photographs actually first saw the light of the day when the Globe magazine published them in the early 1997. In the end, the tabloid was pressured to revoke its controversial content (Conrad 142), while the individuals who stole and released the photographs faced legal consequences (CNN Interactive 1997). Yet, nowadays such autopsy and crime scene photographs are easily accessible online, and one can come across them involuntarily via Google Search. Arguably, this accessibility has contributed to the waning of their shock value, and so the vids containing drastic images are now often deemed tolerable. It remains debatable though to what extent the vidders' use of them is different from what the Globe magazine did in 1997. Perhaps the online circulation of the graphic photographs is yet another manifestation of the widespread fascination with JonBenét's body-both living and dead. As Blaine writes, "We are even invited to become armchair detectives, perusing JonBenét's body with quasi-gynecological specificity .... No part of her body remains private, presumably because the public has a right to know" (58). Analogically, one can argue that some of the vidders treat 
JonBenét's (dead) body as a mere tool of (quasi)artistic enquiry. The right to (quasi)artistic expression thus supersedes JonBenét's and her family's right to privacy, making the vidders in question into ironic figures, not very different from the media which they often criticize.

Even though JonBenét vidders reach for such explicitly graphic materials only occasionally, quite a few seem fond of retelling the Ramsey case in a melodramatic fashion. Predictably, instead of recontextualizing JonBenét as an "ordinary girl," this strategy often constructs the JonBenét vid character as a gothic heroine in a tale of twisted passion and death. Importantly, Kincaid argues that such a narrative and aesthetic formula-a "gothic melodrama"-is actually commonly employed in contemporary, English-language accounts of child (sexual) abuse (Child-Loving 341, 356), which in turn makes vid narratives symptomatic rather than exceptional.

TheDoorMouseTeapot's "Cover My Eyes Tonight (The JonBenét Ramsey Case)" serves as an interesting example of the (re)employment of the gothicized formula. Here, the JonBenét vid character appropriates the voice of the singer of The Birthday Massacre, a band putting a modern, electronic spin on gothic ballads. With her gentle, feminine voice, she sings of lost childhood innocence and traumatic events that cause her mental anguish, thus preventing her from forming a stable identity. In one of the more atmospheric moments we see a series of three sepia shots of JonBenét's gravestone decorated with angel figurines, fallen leaves, and a single rose, which then transition to a series of three posed photographs of JonBenét wearing heavy make-up, and having a stern, melancholic expression on her face (01:29-01:48). One of these images shows her in the company of her mother and brother (01:42-01:44), but the aesthetic and the overall atmosphere is completely different from what we can see in the spontaneous family photographs of the Ramseys which the vidders use on other occasions. Although the vid appears indeed to point at the intruder and the media as JonBenét's abusers, this seems ironic since the vid itself constructs JonBenét character as a fascinating if troubled gothic heroine singing her dark tale from beyond the grave-a portrayal which is again oddly consistent with the much-detested narratives of the tabloid media that vidders often claim to oppose.

\section{Conclusions}

Concluding my brief portrayal of the JonBenét Ramsey YouTube memorial community, it seems important to ask whether JonBenét vidders are in any way successful in their attempts to construct a narrative countering the media accounts of the Ramsey case? Admittedly, it cannot be denied that they indeed contribute to the circulation of JonBenét's non-pageant images which allows many to come to see JonBenét Ramsey in a different way than through the prism of the pageant persona. Still, it is also hard to deny that while trying to recover JonBenét the "ordinary girl," vidders often end up reinforcing the image of JonBenét as a peculiar child-woman hybrid, a troubling being on whom various fears and desires can be collectively and individually projected. In this sense, the vidders' attempts at recontextualizing JonBenét as "an average little girl" prove lacking. I argue that what the vids eventually present is a JonBenét character reimagined as an illustration of cultural myths, predominantly the ideal of an ever-innocent and beautiful child. (The ideal whose cultivation inevitably leads to a simultaneous creation of its mirror image-the erotic child). Thus, even though vidders 
attempt to use new media to oppose the narratives promoted by mainstream media, their goal is a simultaneous sustaining rather than challenging of the larger cultural narratives surrounding the concepts of childhood and family, with all the cultural legacy that these entail.

51 Although JonBenét vids constitute an example of polemical remixes which use materials provided by mainstream media to challenge their message and enter into an argument regarding cultural values, the subjugation of the vulnerable and their (mis)representations, they also provide an apt illustration showing that the nature and results of such socio-cultural disputes may be complex enough so that neither side can be effectively labeled "progressive" or "conservative." I suggest that perhaps more caution should be adopted against using this kind of labeling in remix and fandom studies-although convenient and accurate in many cases, it may prove distortive in others. The Ramsey case and the emerging broader issue of cultural representation of children have proven to be a topic that eludes such simple classifications, as they seem to pertain to centuries-old cultural dilemmas. Indeed, rather than constituting an isolated problem and an exception, the story of JonBenét Ramsey's life and the peculiar postmortem fame born out of media narratives and their (both passive and active) consumption lends credence to the claim that Anglophone (pop)cultural representations of children and childhood at large are riddled with seemingly irreconcilable contradictions, as the child figure is being simultaneously presented as "good" and "bad" or "innocent" and "erotic." What perhaps should follow is a reflection on how often children's images and stories are used to actually benefit children themselves as opposed to being employed as mere devices communicating adult fears, traumas, and desires.

\section{BIBLIOGRAPHY}

BeautifulSoul. “JonBenet Ramsey | Once upon a December.” YouTube, 12 Dec. 2016, www.youtube.com/watch?v=U6Nz-IJP28c. Accessed 29 Oct. 2017.

Brown, Jeremy. "Why the JonBenét Ramsey Murder Case Matters." Newsweek Special Edition. 22 Sep. 2016, www.newsweek.com/why-JonBenét-ramsey-murder-matters-501733. Accessed 1 March 2019.

Cann, Cadi K. Virtual Memorials: Grieving the Dead in the Twenty-First Century. UP of Kentucky, 2015.

Ciancia, Mariana, and Simone Tosoni. "Vidding and Its Media Territories: A Practice-Centred Approach to User-generated Content Production." Present Scenarios of Media Production and Engagement, edited by Simone Tosoni, Edition Lumiere, 2017, pp. 39-54.

CNN Interactive. “2 arrested in a..." CNN. edition.cnn.com/US/9701/15/boulder.slaying/ index.html. Accessed 29 Oct. 2018.

Coppa, Francesca. “An Editing Room of One's Own: Vidding As Women's Work." Camera Obscura: Feminism, Culture, and Media Studies, vol. 26, no. 2, 2011, pp. 123-130. 
Coppa, Francesca. “Women, Star Trek, and the Early Development of Fannish Vidding." Transformative Works and Cultures, vol. 1, 2008, journal.transformativeworks.org/index.php/ twc/article/view/44/64. Accessed 15 Apr. 2021.

Dean, Michelle. “American Obsession: How JonBenét Ramsey Gave Rise to the Online Detective." The Guardian, 9 Sep. 2016, www.theguardian.com/us-news/2016/sep/09/JonBenét -ramseymurder-20-year-anniversary-online-detectives. Accessed 1 Oct. 2017.

Doss, Erika. Memorial Mania. U of Chicago P, 2010.

Ferrucci, Franco. “The Dead Child: A Romantic Myth.” Modern Language Notes, vol. 104, no. 1, 1989, pp. 117-134.

CherishEarthAngels. "About.” YouTube. www.youtube.com/user/CherishEarthAngels/about. Accessed 9 Oct. 2018.

Conrad, JoAnn. "Docile Bodies of (Im)material Girls: The Fairy-tale Construction of JonBenét Ramsey and Princess Diana.” Marvels \& Tales, vol. 13, no. 2, 1999, pp. 125-169.

ForeverInXWonderland . "Mother's Courage.” YouTube, 4 May 2011, www.youtube.com/watch? v=SfC5uO6qZho. Accessed 11 Oct. 2018.

Gibson, Margaret. "Death and Mourning in Technologically Mediated Culture." Health Sociology Review, vol. 16, no. 5, 2007, pp. 415-424.

Giroux, Henry A. "Nymphet Fantasies: Child Beauty Pageants and the Politics of Innocence". America on the Edge: Henry Giroux on Politics, Culture an Education. Palgrave MacMillan, 2006, pp. 129-150.

Harju, Anu. "Socially Shared Mourning: Construction and Consumption of Collective Memory." New Review of Hypermedia and Multimedia, vol. 21, no.1-2, 2015, pp. 123-145.

HeavensSweetHearts. "Patsy Ramsey tribute-Iris (PLEASE WATCH).” YouTube, 23 March 2010, www.youtube.com/watch?v=AY4Yj41ozuo. Accessed 12 Oct. 2018.

Hideochseek. “JonBenét: See Who I Am.” YouTube, 18 Feb. 2008, www.youtube.com/watch? v=Fze0q0lTPKQ. Accessed 21 Oct. 2018.

Jenkins, Henry. Textual Poachers: Television Fans \& Participatory Culture. Routledge, 1992.

Johnson, Richard. "Exemplary Differences: Mourning (and not Mourning) a Princess." Mourning Diana: Nation, Culture and the Performance of Grief, edited by Adrian Kear and Deborah Lynn Steinberg, Routledge, 1999, pp. 15-39.

Kincaid, James R. Child-Loving: The Erotic Child and Victorian Culture, Routledge, 1994.

Kincaid, James R. "Little Miss Sunshine: America's Obsession with JonBenét Ramsey.” Slate, 21 Aug. 2006, slate.com/culture/2006/08/the-JonBenét -case-examined.html. Accessed 3 Oct. 2017.

Kuhn, Virginia. “The Rhetoric of Remix.” Transformative Works and Cultures, vol. 9, 2012.

journal.transformativeworks.org/index.php/twc/article/view/358/279. Accessed 15 Apr. 2021.

Marcias, Teresa. "Between Violence and Its Representation: Ethics, Archival Research, and the Politics of Knowledge Production in the Telling of Torture Stories." Intersectionalities: A Global Journal of Social Work Analysis, Research, Polity, and Practice, vol. 5, no. 1, 2016, pp. 20-45.

Mills, David and Michael Tracy. Who Killed the Pageant Queen?. ITV, 2004. 
Mitchell, Lisa M. et al. "Death and Grief On-line: Virtual Memorialization and Changing Concepts of Childhood Death and Parental Bereavement on the Internet." Health Sociology Review, vol. 21, no. 4, 2014, pp. 413-431.

NavylittleMonster. "No Address in the Stars § Remembering JonBenét Ramsey." YouTube, 30 Nov. 2014. www.youtube.com/watch?v=aDoP1lwTV-U. Accessed 29 Oct. 2018.

NikkiJ. “JonBenét Ramsey: Young and Beautiful.” YouTube, 31 Jan. 2014. www.youtube.com/ watch?v=UHI7WjGhmJk. Accessed 29 Oct. 2018.

Oates Joyce Carol. “JonBenét Ramsey, America's Most Famous Little Girl. The Paris Review. Republished in: Celestial Timepiece: A Joyce Carol Oates Patchwork, 2001, celestialtimepiece.com/ 2015/12/01/JonBenét-ramsey-americas-most-famous-little-girl/. Accessed 9 Oct. 2018.

Oates, Joyce Carol. “The Mystery of JonBenét Ramsey.” The New York Review of Books, 24 June, 1999. Plotz, Judith. Romanticism and the Vocation of Childhood. Palgrave MacMillan, 2001.

Ramsey, John, and Patsy Ramsey. The Death of Innocence. Thomas Nelson, 2000.

Ramsey John, and Ramsey P. "Interview with Parents of Slain Child Beauty Queen." CNN Aired 1 Jan. 1997, edition.cnn.com/US/9701/11/slain.girl.update/transcript.html. Accessed 29 Oct. 2018.

Remembering JonBenét Ramsey. “About.” Facebook. www.facebook.com/pg/ RememberingJonBenét Ramsey/about/?ref=page_internal. Accessed 10 March 2019.

Schiller, Lawrence. Perfect Murder, Perfect Town: The Uncensored Story of the JonBenét Murder and the Grand Jury's Search for the Truth. HarperTorch, 1999.

Schonig, Jordan. “'Liking' As Creating: On Aesthetic Category Memes.” New Media \& Society, vol. 22, no. 1, 2019, pp. 26-48.

Splee331. "JonBenét Patricia Ramsey || The Child the Media Forgot.” YouTube, 2014.www.youtube.com/watch?v=XDhzN9LlE_k\&list=PLQqbaawB8YGuXIlHvqel58EYa6kXFcIm\&index=29. Accessed 2 Dec. 2017.

Svegaard, Sebastian. "Critical Vidders: Fandom, Critical Theory and Media." Akademisk Kvarter, vol. 11, 2015, pp. 104-114.

TheDoorMouseTeapot. "Cover My Eyes Tonight (The JonBenét Ramsey Case)." YouTube, 5 Feb. 2014. www.youtube.com/watch?v=BOJ97IoZJOk\&t= . Accessed 11 Oct. 2018.

TheDoorMouseTeapot. "Don't Forget Me (Remembering JonBenét Ramsey, 20 Years Later)." YouTube, 25 Dec. 2016. www.youtube.com/watch?v=fgBUym75u3g\&t=. Accessed 2 Dec. 2018.

Tropp Trensky, Anne. “Saintly Child In Nineteenth Century American Fiction.” Prospects, vol. 1 1976, pp. 389-413.

Turk, Tisha. “'Your Own Imagination': Vidding and Vidwatching as Collaborative Interpretation.” Film \& Film Culture, vol. 5, 2010, pp. 88-110.

Wahlberg, Malin. "Youtube Commemoration: Private grief and communal consolation." The YouTube Reader, edited by Pelle Snickars, National Library of Sweden, 2010, pp. 218-235.

Walsh Pasulka, Diana. "A Communion of Little Saints: Nineteenth-Century American Child Hagiographies." Journal of Feminist Studies in Religion, vol. 23, no. 2, pp. 51-67.

Wood, Naomi. "Angelic, Atavistic, Human: The Child of the Victorian Period." The Child in British Literature: Literary Constructions of Childhood, Medieval to Contemporary, edited by Adrienne E. Gavin, Palgrave MacMillan, 2012, pp. 116-130 
York Blaine, Diana. "Necrophilia, Pedophilia, or Both?: The Sexualized Rhetoric of the JonBenét Ramsey Murder Case." Sexual Rhetoric: Media Perspective on Sexuality, Gender and Identity, edited by Meta G. Carstarphen and Susan C. Zavoina, Greenwood P, 1999, pp. 51-62.

\section{ABSTRACTS}

Even over 20 years after her death, JonBenét Ramsey remains the most recognizable child murder victim in recent American history, with her case being especially notorious for its sensational and elaborate media coverage. In this article, I take a look at an Internet community which-through the means of YouTube remixes-attempts to oppose the narratives popularized in the mainstream media, using the Ramsey case to offer counter-representations of the concepts of family, childhood, and girlhood. I also attempt to show that the outcome of this online activism does not correspond fully with the intent, as the videos in question often come close to complicity with the narratives which their authors try to subvert. This observation adds credence to the claim that cultural representations of children and childhood in contemporary English-language discourse at large feature a seemingly irreconcilable combination of sentimental innocence and disquieting eroticism.

\section{INDEX}

Keywords: remix video, memorial video, vidding, social media, YouTube, JonBenét Ramsey, childhood studies, feminist studies

\section{AUTHOR}

\section{SYLWIA GRYCIUK}

Sylwia Gryciuk graduated from the University of Wrocław in 2015. Her M.A. thesis was devoted to female relations in Sylvia Plath's works. In 2017 she began doctoral studies at the University of Wrocław and is currently working on a dissertation concerning fictionalized (re)interpretations of the JonBenét Ramsey murder case present in American literature and media. Her academic interests include American trauma narratives, American childhood discourses, and the American Gothic tradition. 